Jennifer Hillan ${ }^{2}$

There are many things that may cause you to fall, and you can change ENAFS several of them. Here are some easy changes you can make to decrease your risk of falling.

\section{Your Shoes}

Some types of shoes can make you more likely to fall. Try to avoid:

- Walking barefoot

- Wearing high heels

- Wearing shoes with slippery soles

*Wearing shoes with high collars (high-tops) may improve your balance.

\section{Stay Active!}

This is one of the most important things you can do for yourself! Not only does regular activity help keep you healthy, it also can reduce your risk of falls. It can improve your

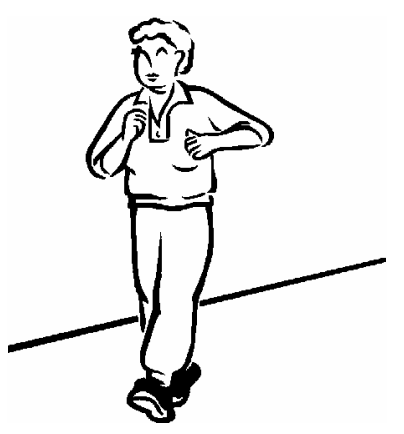
strength, balance, and gait. Walking and gardening are great ways to stay active. Just move your body and have fun!

\section{Limit or Avoid Alcohol}

Alcohol makes you less alert. It can also affect your coordination. If you drink alcohol, you may be more likely to fall. It's best to avoid alcohol or limit yourself to one drink per day.

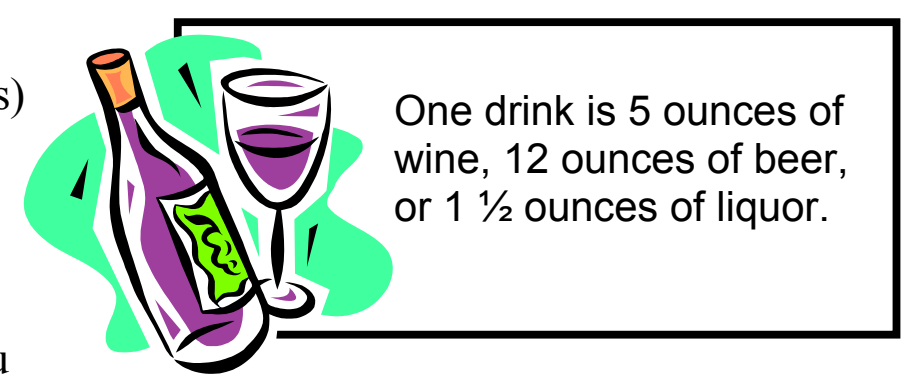

\section{Review Your Medications}

Taking some types of medications may make you more likely to fall. You may also be more likely to fall if you take four or more medications

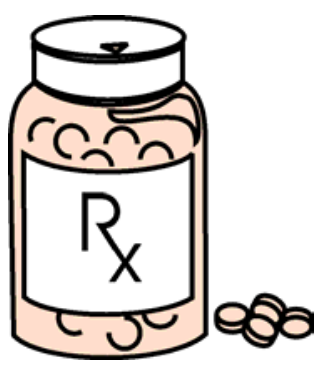
each day. Review your medications with your healthcare provider.

1. This document is FCS2230, one in a series of the Department of Family, Youth and Community Sciences, Florida Cooperative Extension Service, Institute of Food and Agricultural Sciences, University of Florida, Gainesville, FL 32611. Publication date: April 2005. Please visit the EDIS Website at http://edis.ifas.ufl.edu

2. Jennifer Hillan, MSH, RD, LD/N, former ENAFS nutrition educator/trainer, Department of Family, Youth and Community Sciences, Institute of Food and Agricultural Sciences, University of Florida, Gainesville, FL 32611. Reviewed by Linda B. Bobroff, PhD, RD, LD/N, Department of Family, Youth and Community Sciences, University of Florida. 